\title{
Digital Humanities and Renaissance Studies in Canada: A Graduate Student's Perspective
}

\author{
SARAH M. LOOSE \\ University of Toronto
}

This article focuses on digital humanities and Renaissance studies in Canada, highlighting established projects such as Iter and newer efforts such as Serai, and addressing recent interest in historical GIS. This survey of projects demonstrates how the work of Renaissance studies faculty and graduate students in Canada is increasing accessibility to sources, creating new knowledge environments and spaces for collaboration, and encouraging new ways to map and visualize Renaissance data, with an end result that enhances our understanding of the past and the ways that digital technology is changing humanities scholarship. The article also suggests that from the perspective of graduate students, participation in these endeavours provides not only training in digital technologies but also the opportunity to contribute knowledge to the field in concrete ways and the chance to establish a foundation in methodologies and practices that will shape approaches to Renaissance studies research and teaching in the future.

Cet article se penche sur les humanités numériques et les études de la Renaissance au Canada, en présentant des projets établis tels qu'Iter et plus récents tels que Serai, ainsi qu'en examinant l'intérêt plus récent pour le système d'information géographique (SIG) historique. Ce survol de différents projets montre comment le travail de professeurs et d'étudiants aux études supérieures dans le domaine améliore laccès aux sources, créent des environnements pour de nouvelles connaissances et des espaces de collaboration, et favorisent de nouvelles façons de visualiser des données relatives à la Renaissance, enrichissant ainsi notre compréhension du passé, tout en mettant en lumière les transformations des sciences humaines provoquées par les technologies numériques. Cet article avance également quén ce qui concerne les étudiants aux études supérieures, la participation dans ces projets non seulement leur donne de l'expérience en humanités numériques, mais leur donne aussi la chance de pouvoir contribuer de façon concrète à l'avancement des connaissances dans leur domaine. Ces expériences leur donne également lopportunité de développer une méthode et des pratiques qui détermineront leurs approches dans leur recherche et leur enseignement à venir en études de la Renaissance.

igital humanities is a field that defies attempts to place a firm definition
upon it. Once called humanities computing, it refers broadly to the use
of digital tools in humanities research and teaching as well as the study of how 
digital technology impacts knowledge production and distribution. ${ }^{1}$ Over the past decade, digital humanities has rapidly enlarged in participation, scope, recognition, and institutional presence. ${ }^{2}$ The range of methods and applications encompassed by the field is appropriate to humanistic studies since, as Willard McCarty has stated, humanists are "inquirers into transcendent artifacts and events-things and situations which cannot in principle be completely specified and so exhausted by our descriptions of them." 3 The Renaissance, with its connotations of intellectual rebirth and revolution in knowledge-producing technologies, is often invoked as a parallel to the transformative effects of technology on both the world at large and the world of scholarship. Descriptions of this "digital renaissance" frequently link the two phenomena with broad comparisons such as relating the accessibility to information provided by computers and the internet today to the earlier impact of the printing press. Although it is a worthwhile exercise to consider practices of knowledge production in both the pre-modern era and the current digital age, it ought to be managed without resorting to such simplistic comparisons. Few are better placed to question, explore, and critique these issues than the scholars and students who engage with both constructs, practising Renaissance studies and digital humanities.

In honour of the fiftieth anniversary of Renaissance and Reformation/ Renaissance et Réforme ( $R \nLeftarrow R$ ), a journal whose earliest efforts focused entirely on publishing the holdings of resources available for Renaissance studies in Canada, it seems appropriate to dedicate a few pages to some of the ways that scholars of the Renaissance in Canada are both creating access to and producing new resources through digital humanities. ${ }^{4}$ Canadian scholars are among the

1. This definition comes from a consideration of the definitions offered by experts in the field. There is, in fact, an entire website dedicated to definitions of digital humanities: whatisdigitalhumanities.com. The creator of the site, Jason Hepler, compiled answers provided to that question between 2009 and 2012 by participants in the Day of Digital Humanities. Each time visitors refresh the web page a new definition appears. The website thus offers a look at the variety of ways scholars define digital humanities.

2. David M. Berry provides a succinct history of digital humanities in his recent monograph; see Berry, Understanding Digital Humanities (New York: Palgrave Macmillan, 2012), 2-5.

3. Willard McCarty, "Being Reborn: The Humanities, Computing and Styles of Scientific Reasoning," in New Technologies in Renaissance Studies, ed. William R. Bowen and Raymond G. Siemens (Tempe, AZ: Iter and ACMRS, 2008), 6-7.

4. The first four volumes of $R \& R$ published solely information on library and archive holdings of Renaissance primary sources and related secondary materials; see Renaissance and Reformation 1.1-2 (1964) and 3 (1965), 2.1 (1965) and 2-3 (1966), 3.1 (1966) and 3.2-3 (1967), 4.1 (1967) and 4.2-3 (1968). 
leaders in the development and application of digital tools for textual analysis, collaborative research, publication, and teaching, producing work that positively impacts accessibility to sources and creates new knowledge on the Renaissance. These scholars, however, do not work alone; graduate and undergraduate students also play a significant role in digital humanities projects, labouring closely with scholars, librarians, archivists, and IT specialists in a variety of ways. For graduate students, participation in these endeavours provides opportunities for training in digital technologies and the chance to contribute knowledge to the field in concrete ways. Furthermore, as the use of digital research methods and tools increases, engaging in digital humanities enables graduate students to establish a foundation in methodologies and practices that will shape approaches to the research and teaching of Renaissance studies in the future.

Rather than attempt a comprehensive survey of Renaissance digital humanities projects in Canada, this article will instead highlight established, large-scale projects such as Iter and more recent efforts such as Serai to demonstrate how Renaissance studies faculty and graduate students in Canada are contributing to the development of digital tools, increasing accessibility to sources, and producing new knowledge. Additionally, the article will address a growing trend in one specific digital technology: historical GIS. Throughout I will offer my perspective as a graduate student and reflect on the benefits of training and participation in the digital humanities for my own research and growth as a scholar of the Renaissance, as well as the challenges and rewards of engaging in digital scholarship.

The ground-breaking project that stands as one of the most significant Canadian contributions to Renaissance digital humanities is Iter. A key resource for students and scholars of the medieval and Renaissance periods, Iter is dedicated to

creating a sophisticated gateway to all relevant resources which employs a network of bibliographies and databases, and which connects as closely as possible the objects themselves. This gateway [...] is to be comprehensive in scope, timely in its delivery of new information, and accessible to the academic community both with regard to cost and the use of technology. ${ }^{5}$

5. William R. Bowen, "Iter: Building an Effective Knowledge Base," in Bowen and Siemens, eds., New Technologies in Renaissance Studies, 102. 
As such, Iter is at the forefront of the movement to make humanities content available and searchable online. In its current form, Iter seeks to be a knowledge base; an analytical tool as well as a bibliography and finding aid. By linking sources to detailed metadata, Iter offers a searchable network of print and digital resources that enables scholars to retrieve, organize, and assess information according to their own needs. ${ }^{6}$

Part of Iter's success comes from its ability to negotiate collaboration and adapt to changing technologies. Iter began as a partnership, established in 199495 as a joint effort between the Centre for Reformation and Renaissance Studies (CRRS) at Victoria University in the University of Toronto and the Renaissance Society of America (RSA) to create an online bibliography for Renaissance studies. ${ }^{7}$ William R. Bowen, Iter's founding and current director, worked with the assistance of the Centre for Instructional Technology Development at the University of Toronto Scarborough to produce a database of journal articles by 1996. Grants from the Andrew W. Mellon and other foundations, as well as a cross-border partnership with the Arizona Center for Medieval and Renaissance Studies (ACMRS) at Arizona State University, further expanded the bibliography: the indexing of book reviews began in 1997 and the digitization of Paul Oscar Kristeller's Iter Italicum, a finding aid for humanist manuscripts, took place in 1999. It is important to note that these partnerships have created opportunities from 1996 to the present for approximately four hundred graduate and undergraduate students to train and participate in adding content and building the Iter database. Though varied in size and complexity, the sum total of each student contribution and the vast amount of material available through Iter suggests how crucial student participation can be to the success of Renaissance digital projects.

As Iter moved into the new millennium, the scope of the project began to expand and the database increased with the conversion of more finding aids and inventories into online, searchable formats. One of the most recent finding aids is Romeo and Juliet, a database cataloguing Renaissance prompt books.

6. Bowen describes the shift to building Iter as a knowledge base as "a simple-though terrifyingly ambitious-plan"; see Bowen, "Iter," 109.

7. Iter is presently governed by an executive board with Bowen as director, Raymond G. Siemens as associate director, and representatives from the RSA, the Sixteenth Century Society and Conference, the ACMRS, the CRRS, the University of Toronto's Faculty of Information Studies, and the John P. Robarts Library. Additionally, Iter has relationships with other non-profit, academic organizations. 
Furthermore, as the capabilities of digital technologies alter and improve, Iter continues to adapt and adjust its scale. Responding to trends in digital publication, Iter began to make the full text of $R \& R$ available in early 2004. Other journals have since been added, including Quaderni d'italianistica and Early Modern Women: An Interdisciplinary Journal. Branching into the world of e-books, Iter now offers digital versions of series published by the CRRS such as The Other Voice in Early Modern Europe and Essays and Studies, as well as the New Technologies in Medieval and Renaissance Studies series, co-published by Iter and the ACMRS.

Further exploring the idea of Iter as a knowledge base, the newest expansion of the project is Iter Community (IC), an exciting development that moves beyond bibliography, databases, and digital publication to provide a platform for research and the creation of new knowledge. Described by its creators at Iter and the University of Victoria's Electronic Textual Cultures Lab as a "social knowledge creation platform," Iter Community will enable scholars of the Middle Ages and the Renaissance to form research communities online to support and facilitate collaboration and communication on digital humanities projects. This new platform is currently being tested by various research communities, including the Renaissance Knowledge Network, or ReKN, and is scheduled for public release in March 2015. IC looks likely to become another significant Canadian contribution to Renaissance studies and demonstrates how Iter, by continuing to foster collaboration, staying current with digital trends, and moving towards a vision of the project as a knowledge base, serves as a model for other Renaissance digital projects that aspire to offer both practical and analytical tools.

Iter is one of many Canadian digital projects in Renaissance studies that have contributed significantly to the availability of resources through the digitization of text. This includes the creation of digital, searchable versions of both primary and secondary sources, usually through textual encoding using extensible markup language, or XML. ${ }^{8}$ The majority of text-based projects follow XML protocols established by TEI, or Text Encoding Initiative, "a consortium which collectively develops and maintains a standard for the representation of

8. XML is a markup language that allows texts to be searchable and read by both humans and machines. It is more flexible than other markup languages since XML focuses on the content or data within a text, rather than on the appearance of the text. XML is also customizable, rather than having a pre-defined set of tags. 
texts in digital form." ${ }^{\prime 9}$ Renaissance scholars in Canada have made good use of TEI over the past two decades, producing an array of works that offer searchable, interactive versions of print and manuscript prose, verse, and dramatic literature. ${ }^{10}$ One example is Records of Early English Drama (REED), a widely used collection of primary sources relating to theatre and performance in England spanning from the Middle Ages to 1642. Based at the University of Toronto with collaborators in both the United Kingdom and the United States, REED began as a printed source but in recent years has become a digital project. To date, REED has converted twenty of its past print volumes into digital PDF format, while a team is also at work creating eREED, an accessible and fully searchable digital publishing format for forthcoming REED collections. ${ }^{11}$ REED scholars have also developed the Early Modern London Theatres database, a searchable online collection of primary sources related to twelve London theatres.

Like REED, many text-based projects focus on a particular manuscript, type, or set of documents or sources. The Electronic Textual Cultures Lab (ETCL), housed at the University of Victoria and directed by Renaissance scholar Raymond G. Siemens, brings together these kinds of projects and is populated by researchers, programmers, faculty, graduate students, and postdoctoral fellows studying textual communication in the past and the present. The ETCL supports a variety of Renaissance text-centered digital projects ranging in scope and impact. The largest project at the ETCL is Implementing New Knowledge Environments (INKE), an international and interdisciplinary research initiative funded by the Social Sciences and Humanities Research Council of Canada's Major Collaborative Research Initiatives program. Headed by Siemens, this project features scholars and graduate students across Canada joining forces with other students and researchers around the world to explore how practices of reading and communication in the past might help us

9. See the TEI homepage: http://www.tei-c.org/index.xml.

10. For an overview and discussion of tools and projects related to the digitization and encoding of text, see Brent Nelson and Melissa Terras, eds., Digitizing Medieval and Early Modern Material Culture, New Technologies in Medieval and Renaissance Studies Series 3 (Tempe, AZ: Iter and ACMRS, 2012).

11. A prototype version of eREED was completed in 2012; see Jason Boyd and John Bradley with Carolyn Black, Sally-Beth MacLean, and Paul Vetch for the Fortune Theatre Records (FTR) Project Team, "The Fortune Theatre Records: A Prototype Digital Edition, Records of Early English Drama (REED): White Paper," REED website, 2013, http://reed.utoronto.ca/wp-content/uploads/2013/12/ FortuneWhitePaper.pdf. 
understand the future of reading and the book in the digital age. Scholars involved in this ground-breaking project are working on prototypes of various tools and interfaces for digital reading that take into account an understanding of book making, practices of reading, knowledge production, and communication from the Renaissance to the present. Beyond creating new digital tools, INKE stands as a significant example of the ways in which Canadian Renaissance scholars are at the forefront of seeking to apply an understanding of communication technology in the past to the ways that we think about and use digital technology today.

In addition to the large-scale impact of projects like INKE, the ETCL also hosts a number of smaller undertakings. Among them is Siemens's own Devonshire Manuscript project, a textually encoded edition of a sixteenthcentury verse miscellany that seeks to highlight the social and extra-textual elements of the manuscript. Combining print and digital traditions, a critical edition of the manuscript will be published as part of Iter's Medieval and Renaissance Texts and Studies Series in 2015, while a fully encoded digital version of the manuscript will be housed on Iter Community. ${ }^{12}$ Another project proposed by scholars at the ETCL is the creation of a fully searchable critical source database for Shakespeare's sonnets. Likewise, combining both text and images, Claire Carlin, also a professor at the University of Victoria, has produced an online anthology, Le Marriage sous l'Ancien Regime, as a resource for depictions of marriage in seventeenth-century France.

In addition to supporting the study of digital tools and textual communication among its faculty, staff, students, and collaborators, the ETCL has hosted a yearly Digital Humanities Summer Institute (DHSI). Open to faculty, staff, and students, for the past ten years the DHSI has attracted digital humanities experts from around the world to lead intensive workshops and seminars to train participants in a wide variety of digital tools and methods, from data mining and text analysis to TEI and data visualization. For graduate students, the DHSI represents an unparalleled opportunity to join the digital humanities community and gain valuable experience. Participants can even receive

12. Raymond Siemens, Karen Armstrong, Constance Crompton, and the Devonshire MS Editorial Group, A Social Edition of the Devonshire Manuscript (BL MS Add 17,492), New Technologies in Medieval and Renaissance Studies 5 (Toronto: Iter Academic Press, 2015). Prior to the 2015 public release of Iter Community, the Devonshire Manuscript project can be found online at the address listed at the end of this article. 
academic accreditation through obtaining a Graduate Certificate in Digital Humanities. This kind of training and accreditation addresses concerns over how to credit and account for digital training as evidence of scholarly activity, something that is crucial for graduate students and junior faculty seeking to enter the job market and build careers in academia.

Initiatives like REED, the ETCL, and the DHSI are representative of many other significant contributions made by Canadian scholars using digital methods and technologies to increase accessibility to Renaissance primary sources and to change the way we think about the field. By encoding texts and creating source databases, the faculty and graduate students involved in these projects are opening new avenues of research and fostering the creation of knowledge. This is true not only for the study of literature and texts; Canadian scholars are also seeking to use digital methods of network visualization and analysis to explore themes of cross-cultural interaction, translation, and the transmission of knowledge, practices, and beliefs. One such project is The Hispanic Baroque: Complexity in the First Atlantic Culture, whose website puts forward its aim to "study the origin, evolution, transmission and effectiveness of the baroque patterns of behaviour and representation in the Hispanic world." With an executive committee of scholars across Canada, The Hispanic Baroque is an ambitious, ongoing project that uses digital tools to bring together scholars from around the world and to visualize patterns of cultural change over time. ${ }^{13}$

As already suggested by the development of platforms like Iter Community, digital technologies not only provide new means to study and analyze networks in the past; they can also be used to build networks of collaboration between scholars today, including graduate students, post-doctoral fellows, and junior faculty. My own involvement in digital humanities began at the University of Toronto in 2008 when Natalie Rothman invited me to work as a research assistant on one such project: the development of an online portal dedicated to scholarship on the Mediterranean. The inspiration for the portal grew out of a two-day conference held at the University of Toronto in October 2007, which focused on networks of interaction in the early modern

13. The executive committee of The Hispanic Baroque includes Beatriz de Alba-Koch (University of Victoria), Ricardo Castro (McGill University), Jesús Pérez Magallón (McGill University), Walter Moser (University of Ottawa), and Juan Luis Suárez (Western University). 
Mediterranean. ${ }^{14}$ During a group session on digital resources, participants discussed the possibility of creating a website to facilitate collaboration between scholars at universities across North America, Europe, and the Mediterranean. As a result of the session, Rothman volunteered to take up the challenge and create an interactive portal. Since its origins the project has undergone several name changes, from E-Med to ePorte, and, most recently, from ePorte to Serai, but the goal to produce an online space that promotes collaboration across institutions, disciplines, and linguistic specializations remains the same. ${ }^{15}$

Like Iter, REED, and the ETCL, Serai has also benefitted from crossborder collaborations and expanded its scope over time. The University of Toronto Scarborough is the host and major sponsor of Serai, along with various partners from 2009 to the present. These include relationships with Heidelberg University and the Central European University in Budapest from 2009 to 2011 and a 2013 merger with Serai, an initiative based at the University of Maryland and designed to bring together scholars studying cultural encounters between Europe, the Mediterranean, and the Indian Ocean in an effort to "re-map" the Renaissance. ${ }^{16}$ These partnerships and the merger between ePorte and Serai have helped to shape the project and are reflective of its goal to be a portal for collaboration.

Bringing together Mediterranean studies, the study of cultural encounters, and digital humanities, Serai encourages consideration of the ways that technology can shape current knowledge production and our understanding of the past. ${ }^{17}$ Mediterranean studies is a traditionally and necessarily complex field that crosses disciplinary, spatial, temporal, linguistic, and cultural frontiers. Just as digital technologies update and change, so too the history of the

14. Titled "Networks of Interaction in the Early Modern Mediterranean," the conference was held on October 12-13, 2007. An archived website of conference program, participants, and papers can be found at http://www.utsc.utoronto.ca/ rothman/EMM/participants.html.

15. Serai is hosted online by the University of Toronto Scarborough: http://serai.utsc.utoronto.ca/.

16. The original Serai project began with a summer seminar at the University of Maryland funded by the National Endowment for the Humanities. The original website was moderated by Matt Dimmock, Julia Schleck, and Jyotsna Singh but is no longer available.

17. I must insert a note of thanks to my colleague and fellow graduate student Stephanie Cavanaugh with whom I collaborated for a presentation on Serai at the 2012 Sixteenth Century Society and Conference annual meeting. She has graciously allowed me to adapt a few paragraphs from that presentation for this article. 
Mediterranean is constantly redefined and renegotiated by scholars in the shadow of historians Fernand Braudel, Peregrine Horden, and Nicolas Purcell. ${ }^{18}$ The vision for Serai reflects recent historiographical trends that aim to explore connections and interactions in and around the sea, striving for an inclusive approach. Just as the Mediterranean acted as a mediator and facilitated connections between peoples and cultures along its shores, the Internet and digital tools today serve a similar function, providing people around the world with chances to connect and collaborate. As Paul Blank explained in an article titled "The Pacific: A Mediterranean in the Making?" modern technologies enable us to "reduce the friction of distance" and give us "the reach to be able to create the cultural, political, and economic mix [...] that has characterized the Mediterranean." 19

More explicitly, the goal of Serai is two-fold: first, to promote collaborative research by creating an interface for producing, exchanging, and editing in real time new scholarly resources in a variety of digital formats; second, to facilitate access to existing electronic resources by allowing users to annotate and tag entries to reflect different needs and interests. In order to meet these goals, the Serai team is continuing to work on a number of features such as links to online resources that can be annotated and tagged on our site. These include: virtual museums, galleries, online exhibits, archives, libraries, manuscript and rare book collections, map and image collections, specialized databases, subject bibliographies, dissertations, listservs, journals, and research centres and academic programs. Serai also houses unique inline content consisting of a member directory and member publications, collaborative research projects (databases, transcriptions, and images), guides to archives and other depositories, paleographic guides, and a calendar of events. The site also features an evolving reference library, fully compatible with Zotero, an open-source citation management system. By linking Zotero and Serai, users can automatically update and add content from Serai to their own bibliographies (and vice versa), eliminating the need to enter information multiple times. With the participation of a digital community of scholars, Serai will serve as a virtual meeting

18. Fernand Braudel, The Mediterranean and the Mediterranean World in the Age of Philip II (Berkeley, CA: University of California Press, 1995); Peregrine Horden and Nicolas Purcell, The Corrupting Sea: A Study of Mediterranean History (Oxford: Blackwell, 2000).

19. Paul W. Blank, “The Pacific: A Mediterranean in the Making?" Geographical Review 89.2 (April 1999): 266. 
place, seminar room, library, directory, and laboratory. Ultimately, Serai will be a historical archive in its own right, demonstrating the vitality of digital humanities scholarship.

The process of creating Serai has been an intense learning experience for all involved. Once funding had been obtained from the University of Toronto and the Province of Ontario in 2008, Rothman, Stephanie Cavanaugh (another graduate student) and I began to assemble a critical mass of data with which to launch the website..$^{20}$ Our first step was to create a wiki where we began to accumulate and organize resources in order to launch the website with sufficient content to be useful and inspire others to share resources as well. After we attained an adequate amount of content, the transition from a wiki to a proper website began. The first version of Serai (then called E-Med) was built in HTML, but we immediately recognized that HTML was not flexible enough for the uses we envisioned. Instead, consulting with technical experts, we decided to use Web 2.0 technologies to build the interactive portal we visualized. Geoff Piersol, the technical lead for Serai, asked the steering committee detailed questions about the kinds of users we planned to cater to and the ways that different users might engage with the site. It was instructive to work through the answers to these questions and this process began to show everyone, but especially the graduate students involved, how the use of digital technology could be an intellectual exercise.

A test version of Serai is currently available for public exploration, with the plan for an official launch in 2015. Among the many features currently being refined is the ability of users to create their own groups to discuss and share resources on specific sub-topics of interest. The group setting is one way to curate resources and connect researchers who work on similar projects within the scope of Serai. There are many benefits to operating within this digital platform as opposed to working over email or on a wiki. Users in a Serai group can aggregate and annotate resources, customize group structure and privacy settings, and allocate workspaces for projects and meetings. One of several test groups under construction is centred on Venetian diplomatic interpreters in early modern Istanbul known as dragomans. Created by Natalie Rothman, this group intends to develop a detailed aggregate profile of the dragoman core 
and its representational practices. The Dragoman group will ultimately provide tools and data sets for such research, including a bio-bibliographical database of archival textual and visual materials relevant to the 116 dragomans who worked with Venetian diplomats in Istanbul from 1550 to 1700 . Also planned is a database of English summaries and partial transcriptions of dragoman-related material held in various archives, annotated glossaries of Ottoman and Venetian genres, magistracies, and place names, and a continually evolving bibliography of scholarship on dragomans and other early modern Mediterranean cultural intermediaries. Through providing a platform for collaboration and the creation of groups like the Dragoman group, Serai will enable scholars from across the globe to collaboratively construct their own curated knowledge bases.

The groups feature on Serai has also been put to use in another way: similar to the ETCL's creation and hosting of the DHSI but smaller in scale, Serai has hosted three summer institutes centred on digital scholarship and pre-modern Mediterranean studies. Called the Roots and Routes Summer Institutes (RRSI), these seminars focused on facilitating a trans-disciplinary analytical framework for Mediterranean studies through the use of digital tools and methodologies. The institutes were organized around three thematic clusters: "Spatialities and Borderlands" (2011), "Translation, Mediation, and Circulation" (2012); and "Sociability and Materiality" (2014). Participants, composed mainly of graduate students with some faculty in attendance, had the opportunity to intensively engage with these themes while receiving training from international and local experts in digital tools and methodologies. ${ }^{21}$ The positive impact of this training on graduate students was particularly visible in those who attended multiple institutes; at the 2014 meeting several graduate students not only acted as participants but also taught workshops on digital tools. As interest in digital humanities continues to grow across the field, faculty and students can look to Canadian initiatives like the RRSI and the DHSI (which encourages proposals from participants for course offerings) as models for providing training and involving participants in teaching on both large and small scales.

In addition to textual encoding and the creation of new knowledge environments, another developing area of digital humanities to which Renaissance 
faculty and graduate students in Canada are contributing is "historical GIS." GIS, or geographic information systems, is software that "enables one to display and analyze any kind of information that can be located on the face of the earth, or any other place with known location."22 Since most texts and objects are related to particular locations, GIS can be used to visualize nearly all the information Renaissance scholars study. From Petrarchan sonnets, state tax rolls, and inquisition records, to Elizabethan dramas, chapel decoration, and diplomatic correspondence, the possibilities are manifold. If the question of location or other geographical information is important to an analysis of evidence, and if that analysis would benefit from the visual representation of movement or change over time, then GIS offers one way to carry out such research. ${ }^{23}$ In Placing History, Anne Kelley Knowles provides a useful categorization of GIS applications for history: study of land use and spatial economy (e.g., economic activity, trade networks, diasporas), reconstructing past landscapes (both cities and countryside), and infrastructure projects (demographic and social data). ${ }^{24}$ Of course, as Paul Ell and Ian Gregory succinctly point out: "None of these are impossible without GIS, but all may be made significantly easier by using it." 25

Taking this explanation of the capacity GIS one step further, Jennifer Bonnell and Marcel Fortin state that

Historians have long used maps to investigate, research, and teach history, but GIS greatly enhances the potential of this work by enabling the manipulation, analysis, and output of location information within the historical landscape. [...] With its capacity to integrate and layer divergent

22. Anne Kelley Knowles and Amy Hillier, eds., Placing History: How Maps, Spatial Data and GIS are Changing Historical Scholarship (Redlands, CA: ESRI Press, 2008), xiii. For a more technical definition of GIS, see Ian Gregory and Paul Ell, Historical GIS: Technologies, Methodologies and Scholarship (Cambridge: Cambridge University Press, 2008), 3-5.

23. It is easy to treat GIS software as a tool rather than a method or practice. This question has been debated among geographers for more than a decade; see Dawn J. Wright, Michael F. Goodchild, and James D. Proctor, "Demystifying the Persistent Ambiguity of GIS as 'Tool' Versus 'Science,"” The Annals of the Association of American Geographers 87.2 (1997): 346-62; also Knowles, "GIS and History," in Knowles and Hillier, eds., Placing History, 7.

24. Knowles, "GIS and History," 8-14.

25. Gregory and Ell, 10. 
source materials and tie them to specific locations in space, GIS effectively enables the creation of new source materials. ${ }^{26}$

Thus, historical GIS should be viewed not as a means of generating illustration but as "a means of doing research; it generates questions that might otherwise go unasked, it reveals historical relations that might otherwise go unnoticed, and it undermines, or substantiates, stories upon which we build our own versions of the past." ${ }^{27}$ This attitude reflects current discussions within digital humanities broadly: it is no longer enough to simply use digital tools as a way to organize information or generate illustrations; instead, we need to consider and use them as part of our analytical methods.

According to Renaissance scholar J. B. Owens, GIS offers potential to historians "because [historians] normally deal with processes in complex, dynamic, nonlinear systems and, therefore, demand a means to organize a large number of variables and identify those variables most likely implicated in the stability and transformation of such systems." ${ }^{28}$ Owens, who traces his own interest in GIS to his first encounter with Braudel's iconic work on the Mediterranean and Braudel's efforts to ground early modern Mediterranean history in the physical environment of the sea and its surroundings, argues that the visualization potential of GIS can help historians to overcome the challenges associated with using text as the means of communicating the multidimensional systems we study. ${ }^{29}$ Richard White explained this another way when he stated that "Relationships that jump out when presented in a spatial format such as a map tend to clog a narrative, choking its arteries until-even if the narrative does not expire-the reader, overwhelmed by detail, is ready to die of tedium and confusion." ${ }^{30}$ What these perspectives on GIS suggest is that scholars ought to use GIS technology not only to produce maps to illustrate their work, but also as a tool for the organization and exploration of historical data, whether on local or large, transnational scales. Disciplinary trends

26. Jennifer Bonnell and Marcel Fortin, eds., Historical GIS Research in Canada (Calgary: University of Calgary Press, 2014), xi.

27. Bonnell and Fortin, xi.

28. J. B. Owens, "What Historians Want from GIS," ArcNews (Summer 2007), accessed 11 March 2014, http://www.esri.com/news/arcnews/summer07articles/what-historians-want.html.

29. Owens, "What Historians Want from GIS."

30. Richard White, "Foreword," in Knowles and Hillier, eds., Placing History, x. 
in Renaissance studies-including the issue of spaces (urban, sacred, public, private, etc.), the production, publication, and circulation of texts, and recent efforts to study sensory history-all have potential to benefit from GIS.

A brief example from my own work on Siena's largest charitable institution, the Ospedale di Santa Maria della Scala, during the sixteenth century illustrates, in a small way, the potential of GIS. ${ }^{31}$ Part of my interest in this particular hospital lies in its vast network of farms and subject hospitals both within and without the borders of the Sienese state. Many of the archival documents related to Santa Maria della Scala provide details and evidence regarding the nature of relationships and exchanges between the hospital and its outlying properties. To better understand this charitable network and its contribution to the hospital's political and economic power in Siena, I wanted to visualize and explore these relationships. After looking at several options, I settled on GIS mapping as the best way to display and enhance my data. I then spent a good deal of time reading manuals and using program tutorials to gain a basic working knowledge of ArcGIS, a well-known licensed GIS program. Combining my own efforts with the assistance of the wonderful staff at the University of Toronto's Map and Data library, I began to explore the possibilities of GIS for the representation of my historical data.

Among the documents and data I have mapped to this point is a collection of 120 letters authored by Scipione di Mariano Venturi, rector of Santa Maria della Scala from 1552 to $1562 .^{32}$ The letters span the years of Siena's war with Florence and Spain (1552-55) and have over fifty different recipients, several of whom Venturi corresponded with regularly. Since GIS builds maps through the addition of various data layers, I divided the letters by year and created four spreadsheets with the name of the recipient, the recipient's location (including longitude and latitude data), and the frequency of correspondence with the recipient during that year. Adding this information in layers gave me the option to display one year on its own, or two, or all four years together. ArcGIS also contains a tool that allows data points to be given value, so I used

31. For more on the history of Santa Maria della Scala see Michele Pellegrini, La communità ospedaliera di Santa Maria della Scala e il suo più antico statuto (Siena: Pacini, 2005) and Beatrice Sordini, Dentro l'antico ospedale: Santa Maria della Scala, uomini, cose e spazi di vita nella Siena medievale (Siena: Protagon, 2010).

32. Housed in the Archivio di Stato di Siena (A.S.S.), the letters are scribe's copies bound in a volume of 288 folios; see A.S.S., Ospedale di Santa Maria della Scala, Copia Lettere, N. 436. 
this to display the frequency or number of letters sent to various locations and individuals, allowing me to visualize this data with the size and colour of the plotted points or in bar graph format.

Chronology was only one of many ways to categorize the data; other options included using the recipients or contents of the letters as the organizing principle. However, chronology seemed best suited to place the letters in the context of a series of events that comprised the war. The resulting GIS visualization of Venturi's letters highlighted key connections and interactions that defined Santa Maria della Scala and its network during a time of crisis. The picture that emerged of the role this rector and his correspondence played in negotiating relationships between the hospital, its network, and Siena's enemies during the war contributed to my larger study of the hospital across the sixteenth century, providing evidence of Santa Maria della Scala's activity as an agency of the Sienese state and its importance as a civic resource. Furthermore, mapping the letters also demonstrated the somewhat surprising frequency of Venturi's correspondence with Cosimo I de' Medici and lent credence to a (then) unconfirmed sense gleaned from other sources that Cosimo I recognized the power of the hospital early on and purposely cultivated a positive relationship with the institution. The fruits of this relationship came to bear after the war when Siena became part of the Tuscan state and Cosimo I used Santa Maria della Scala as part of his strategy to consolidate power in Siena.

This is just one, admittedly unsophisticated, example of several sets of documents whose data I intend to map to explore Santa Maria della Scala's charitable network, but it is, I hope, still effective in suggesting the potential of GIS for examining even the most basic humanities data. Beyond this, there is a wide range of possibilities represented by other Canadian GIS projects, like The Map of Early Modern London, DECIMA: The Digitally Encoded Census Information Mapping and Archive, and the REED: Patrons and Performances interactive maps. Each of these projects is an impressive example of how period maps can be used to geo-locate texts, people, objects, and census data among other things. For instance, The Map of Early Modern London uses a digitization of the 1560s Agas woodcut map of London to locate primary texts such as John Stow's Survey of London. ${ }^{33}$ Visitors to the project website can search

33. According to the description on the project website, The Map of Early Modern London is "comprised of four distinct, interoperable projects: a digital Map and gazetteer based on the 1560s Agas woodcut map of London; an Encyclopedia of London people, places, topics, and terms; a Library of marked-up 
sections of the map and click on designated locations to see explanatory articles and links to documents related to that specific location. Similarly, the DECIMA project encodes street by street data from the Florentine tax census of 1561-62 (including tax assessments, inhabitants, occupations, etc.) onto the 1584 Buonsignori map of Florence. At the time of writing, one quarter of the city, Santa Maria Novella, is available for users to search, map, and explore a variety of social and economic data. ${ }^{34}$ As the other quarters of the city are added, the DECIMA team hopes that scholars will contribute their own archival data to be embedded in the map, enhancing the map's uses as a research and teaching tool. Combining both period and modern cartography, the interactive maps of REED's Patrons and Performances project allows scholars and students to view, search, and trace specific performances, acting troupes, venues, and patrons in sixteenth- and early seventeenth-century England and Wales.

Whether focused on digitizing text, creating new tools for research, or using historical GIS, each of the projects surveyed above shares a common element: the participation of graduate students. It is an oft-repeated assumption regarding digital humanities that graduate students and younger faculty are more likely to be involved in developing and carrying out digital projects. But, as Patrik Svensson suggested while citing a study conducted by the University of California, junior scholars actually tend to be more conservative when it comes to change within a discipline. ${ }^{35}$ There are several reasons for this, but chief among them, according to the study, is the pressure of tenure criteria. Since the means of evaluating and crediting digital scholarship is still under debate, young scholars in some cases feel pressured to pursue research and publication that will put them on the tenure-track rather than digital humanities. For graduate students in Renaissance studies confronting the demands of course work, comprehensive exams, language and paleography training, as well as researching and writing a dissertation, engagement in the digital humanities can seem overwhelming and costly in terms of the time and effort it takes to

texts rich in London toponyms, and a versioned edition of John Stow's Survey of London." See http:// mapoflondon.uvic.ca/about.htm.

34. To view the map and explore the census data, see the DECIMA website at: http://decima.chass. utoronto.ca/.

35. Patrik Svensson, "Envisioning the Digital Humanities," Digital Humanities Quarterly 6.1 (2012), accessed 16 February 2014, http://digitalhumanities.org/dhq/vol/6/1/000112/000112.html. 
learn digital methods and tools, especially if one is in an academic environment lacking supportive infrastructure for digital humanities training and research.

Addressing and altering this perspective is one of the ongoing challenges within digital humanities. What I hope this article has shown, however, is that Renaissance digital humanities initiatives in Canada are confronting these issues and seeking solutions by providing a clearer path for graduate students and scholars to follow into digital humanities. In addition to projects like Iter, REED, ETCL, DHSI, Serai, The Map of Early Modern London, and DECIMA, all of which actively train and involve students (both graduate and undergraduate) and post-doctoral fellows, a growing number of Canadian universities like Victoria, Alberta, Brock, Western, and McGill have programs and/or institutes dedicated to digital humanities (many of these run and populated by scholars of the Renaissance) with others likely to appear in coming years. ${ }^{36}$ Additionally, significant digital work is underway at many institutions which may lack a digital humanities program or centre but still offer support and give place for digital research in various schools, departments, and working groups. As digital humanities moves forward, Canadian students, faculty, and administrators in the humanities should continue working together to grow the field.

On this fiftieth anniversary of a journal that published and spread knowledge to help build Renaissance studies in Canada, it is satisfying to note that the projects surveyed here, along with many others, demonstrate that the combination of digital humanities and Renaissance studies in Canada certainly meets $R \& R$ 's original goals. Renaissance digital humanities in Canada has yielded increased accessibility to sources, created new knowledge environments and spaces for collaboration, and encouraged new ways to map and visualize

36. The University of Alberta's Humanities Computing Program, established in 2001, is one of the earliest digital humanities programs in Canada and ranks among the top degree-granting digital humanities programs in the country. The University of Victoria's Faculty of Humanities maintains the Electronic Textual Cultures Lab, while the Humanities Computing and Media Centre offers technical support and assistance for the research and the development of digital humanities projects. Brock University is home to a Centre for Digital Humanities that offers courses to students in a number of departments and provides support and technical services to faculty and students. The CulturePlex Lab: Cultural Complexity and Digital Humanities at Western University is dedicated to developing tools for analysis and visualization to support humanities projects and serves as home to graduate students, faculty, and post-doctoral fellows from across the humanities. McGill University's Digital Humanities Initiative supports over forty digital humanities projects from scholars and students in the Faculties of Arts, Music, and Religious Studies, and the McGill Libraries. 
Renaissance data, all with an end result that enhances our understanding of the past and the ways that digital technology is changing humanities scholarship today. In a recent review essay of digital humanities projects published in Renaissance Quarterly, Canadian scholar of early modern literature and digital humanities Michael Ullyot argued that "the best databases of cultural objects offer new ways of accessing and reconfiguring them, [and] also promise to transform the scholarly arguments we make about them., ${ }^{37}$ Looking to the future, Ullyot then quoted Michael Witmore who at the 2013 Modern Language Association annual meeting stated: "If the field of digital humanities is successful, it will disappear." ${ }^{\prime 38}$ As Witmore implies, digital humanities is poised to become the humanities, as researchers, faculty, and graduate students work together to understand how technology transforms humanities practices and seek to demonstrate the significance of these transformations to our understanding of humanity's past. This is precisely the kind of work in which the projects surveyed above are engaged. If the past twenty years is any indication, Canadian scholars of digital humanities and the Renaissance, faculty and graduate students alike, will continue to seek solutions to the challenges of digital humanities and make significant contributions to shape the future of the field.

\section{List of Digital Projects Mentioned Above}

DECIMA: The Digitally Encoded Census Information Mapping and Archive: http://decima.chass.utoronto.ca/

Devonshire Manuscript Project: http://en.wikibooks.org/wiki/The_Devonshire_ Manuscript

Early Modern London Theatres (EMLoT): http://www.emlot.kcl.ac.uk/

Electronic Textual Cultures Lab: http://etcl.uvic.ca/projects/

The Hispanic Baroque: Complexity in the First Atlantic Culture: http://www. hispanicbaroque.ca/

INKE: Implementing New Knowledge Environments: http://inke.ca/ 
Iter: Gateway to the Middle Ages and Renaissance: http://www.itergateway.org/

Iter Community: http://www.itercommunity.org/

Le Marriage sous l'Ancien Regime: http://mariage.uvic.ca/

The Map of Early Modern London: http://mapoflondon.uvic.ca/

Records of Early English Drama (REED): http://reed.utoronto.ca/

REED Patrons and Performances: http://link.library.utoronto.ca/reed/

Serai: http://serai.utsc.utoronto.ca/

Text Encoding Initiative (TEI): http://www.tei-c.org/

\section{List of Digital Humanities Centres and Initiatives Mentioned Above}

Centre for Digital Humanities, Brock University: http://www.brocku.ca/ humanities/departments-and-centres/digital-humanities

The CulturePlex Lab: Cultural Complexity and Digital Humanities, Western University, http://www.cultureplex.ca

The Digital Humanities Initiative, McGill University: http://www.mcgill.ca/ digital-humanities

Electronic Textual Cultures Laboratory, University of Victoria: http://etcl.uvic.ca/ Humanities Computing and Media Centre, University of Victoria: http://web. uvic.ca/

Humanities Computing Program, University of Alberta: http://www.ois.ualberta.ca/en/HumanitiesComputing.aspx 